\title{
Furia pop. \\ Recepción crítica y exploraciones de un imaginario popular en el arte de los años sesenta en Chile \\ Soledad García Saavedra
}

Recibido: 30.3.19

Aceptado: 26.4 .19

Publicado: 30.6.19

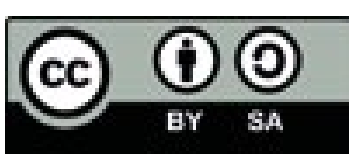

Cómo citar este artículo:

García Saavedra, S., 2019. Furia Pop, recepción crítica y exploraciones de un imaginario popular en el arte de los años sesenta en Chile. Inmaterial. Diseño, Arte y Sociedad. 4(7), pp. 45-69 


\section{Abstract}

Within an environment of social and political transformations along with the rejection of a tradition that took roots in modernism, barge in a pop art in Chile. In comparative modus, this essay looks over a set of international and local controversies, that put in tension the North and the South in the second mid of the sixties and, that trigger out critical receptions about Pop. It examines the immersion of an art in its own reality along with aesthetic, philosophical and political issues through the artworks of artists Francisco Brugnoli, Valentina Cruz, Virginia Errázuriz and Guillermo Núñez, whose artistic positions and motivations arise from a political and popular imaginary.

Keywords

pop art, popular and political imaginary, art critique. 


\section{Resumen}

En un ambiente de transformaciones sociales y políticas, junto con el rechazo de una tradición enraizada en el modernismo, irrumpe un arte pop en Chile. A modo comparativo, este ensayo repasa un conjunto de polémicas internacionales y locales que tensionan el norte y el sur en la segunda mitad de los años sesenta y que desatan recepciones críticas del pop. Se examina la inmersión de un arte en su propia realidad, así como problemáticas estéticas, filosóficas y políticas a partir de las obras de los artistas Francisco Brugnoli, Valentina Cruz, Virginia Errázuriz y Guillermo Núñez, cuyas posiciones y motivaciones surgen desde un imaginario popular y político.

Palabras clave

arte pop, imaginario popular y político, crítica de arte. 
A mediados de los años sesenta, las resonancias del arte pop movilizaron en Chile un estado de críticas a contracorriente de los valores y las estéticas brillantes y afirmativas que la cultura comercial del pop art de Estados Unidos irradiaba por el mundo. La abundante y expansiva propagación del arte estadounidense contó con una atractiva voracidad por parte de la crítica de la prensa angloamericana, cuyo entusiasmo por la frescura y el vértigo de esta nueva invención extrovertida provocó no solo el encanto de los escritores de la prensa y el ascenso de una diseminación internacional que ningún movimiento de las artes visuales hubiera experimentado antes (Madoff, 1997), sino también aproximaciones rápidas y repetitivas de su terminología, generando mitos y malentendidos.

Este ensayo se adentra en la recepción, asimilación y discusiones sobre el arte pop en Chile en medio de la coyuntura internacional de la segunda mitad de los años sesenta con el propósito de explorar las resonancias y distinciones de un arte que, mediado por la prensa anglosajona de alcance internacional, contó con debates, apropiaciones y distinciones artísticas propios de las transformaciones sociales y políticas que se vivían en el Cono Sur. En un primer momento, se busca distinguir las diferencias y similitudes de opiniones críticas que aparecen tanto en Estados Unidos como en Chile cuando el arte pop alcanza su primacía mundial en la Bienal de Venecia de 1964: ¿cómo el contacto con un arte que fue transmitido por la prensa animó debates, aprobaciones y rechazos en distintas localidades? Este texto observa los desencuentros que tuvo la crítica con el arte pop atendiendo al argumento de sus descalificaciones para reconocer, como contrapunto del arte norteamericano, la marginalidad de su acogida en Chile. A partir de fuentes secundarias, se realizan análisis comparativos entre la recepción crítica del norte y la del sur con el propósito de explorar las estéticas discrepantes de acuerdo a las reacciones de críticos y las motivaciones de los artistas. Se introducen las irrupciones de un arte cuyo carácter es político y está inserto en un imaginario popular, en un contexto donde se tensionan convicciones prerrevolucionarias y reformas estructurales en el país — previamente al gobierno de la Unidad Popular- Por último, se busca revisar, a modo de síntesis, algunas de las cualidades de las obras y las posiciones de artistas como Virginia Errázuriz, Francisco Brugnoli, Guillermo Núñez o Valentina Cruz, quienes, en sus distintas versiones, confrontaron a través de sus prácticas artísticas cuestiones estéticas, ideológicas y filosóficas sobre el cuerpo popular y político del ser humano. 


\section{Polémicas y destrucciones del pop}

Como un cordón umbilical que nutre a dos cuerpos, los medios de masas fueron inseparables del arte pop. La apropiación recíproca de unos y otro fue abundante y no se limitó a las reglas ni a la cantidad. El mismo artista Robert Rauschenberg, catalogado como precursor de este movimiento, afirmaba en una entrevista que le interesaba "hacer buen periodismo" (Romera, 1965, p. 276). Apropiándose de imágenes de la prensa incorporándolas en su obra y aplicando pintura sobre su superficie, Rauschenberg denominó su trabajo con el apelativo de "combines", una unión accidentada entre serigrafía, collage, objetos encontrados al azar y pintura de brochazos rápidos con imágenes de fácil reconocimiento. Los objetos de uso cotidiano como billetes, llaves, zapatos y carteles de publicidad compartieron la misma superficie con reproducciones de la contingencia política, la carrera espacial, el deporte y el arte culto: detalles o escenas de pinturas clásicas que aportaban referencias para unir un puzle de múltiples sentidos. De ese periodo, su obra Buffalo II, de 1964, cuyo ensamble de imágenes engrandecía el retrato del presidente recientemente asesinado, John F. Kennedy, constituyó un recuerdo tácito de su muerte y un mosaico iconográfico, compuesto de un águila, una llave, un helicóptero militar y un paracaídas de un astronauta, entre otros, generando una trama de asociaciones simbólicas. Esta imagen apareció reproducida en revistas en Chile y en el mundo cuando dieron a conocer la polémica noticia de la obtención por parte del artista del Gran Premio de Pintura en la XXXII Bienal de Venecia.

En Santiago, el entonces director del Museo de Arte Popular Americano y profesor de la Facultad de Bellas Artes, Tomás Lago, publicó en la revista Ercilla el artículo "Escándalo en Venecia". Luego de un viaje de estudios por Europa, en donde asistió al megaevento italiano, Lago plasmaba el debate que levantó principalmente la crítica francesa al verse destronada la escuela de París de su posición hegemónica, cuyo dominio era ejemplar de los valores artísticos de la pintura y escultura desde fines del siglo XIX. Por primera vez, el premio era otorgado a un artista norteamericano y no a uno francés o europeo. En ese sentido, las obras de Rauschenberg no solo significaban una modificación y destrucción estética de la pintura — que para muchos fue considerada de vulgar-, sino que sobre todo alteraba el horizonte geográfico del mundo del

${ }^{1}$ Además de Rauschenberg, el pabellón curado por Alan R. Salomon reunió obras de Roy Lichtenstein, Claes Oldenburg, Jim Dine y Jasper Johns. Para un análisis de la producción de la exposición en las salas del Arsenal, así como de la producción del catálogo y los comunicados, se recomienda consultar el libro de Hiroko Ikegami The Great Migrator: Robert Rauschenberg and the Global Rise of American Art (MIT Press, 2010). arte, en el que Nueva York relevaba a París. Lago (1964, pp. 12-13), además de intentar definir en su artículo el conjunto de obras pop que el pabellón norteamericano exhibió ${ }^{1}$, aludiendo al remplazo de la imitación del objeto cotidiano "por la realidad de sus motivos y experiencias", la utilización de "materiales deleznables" y, con ello, "la anulación de la trascendencia de la obra artística", citaba las reacciones que las revistas parisinas atribuían a la distinción del 
artista norteamericano como un "falso dadaísta" y a la de su obra como un “dadaísmo retrasado". Aún más: la nota de Lago (1964, p. 13) cerraba con la sentencia del pintor surrealista Giorgio de Chirico, quien declaraba que el pop art no se podía juzgar porque no tenía nada que ver con el arte. Como un combate de críticas y réplicas, el pop art impuso ruido, ruptura y rechazo. Y su confrontación en Chile no estuvo exenta de repudio por parte de la academia, la crítica de arte y el periodismo, quienes, en sus distintos campos, sostenían o encontraban mayores afinidades con la tradición cultural francesa.

Las revistas de arte, música, moda y política replicaron y cubrieron esta nueva tendencia figurativa como un estado de "máxima reacción contra la sociedad y las escuelas anteriores", cuyas fluctuaciones, imprecisiones y, a la vez, obsesiones dejaba entrever. En esa sintonía, el crítico de arte Antonio Romera (1908-1975)2, en la crónica "En torno al pop art", elogiaba "los pegotes de Rauschenberg" por la actitud moral frente al estado de cosas insignificantes, por su "desplazamiento hacia dominios sociales sin compromiso político" ni jerarquías y, sobre todo, por la "antipintura” del artista al renunciar a las normas que hasta ese entonces habían sustentado la representación y el tratamiento del color, el dibujo y la forma (1965, pp. 271-276). En ese sentido, Romera apreciaba las obras de Rauschenberg no tanto por su polémico premio en la Bienal de Venecia como por el "caos representativo" de sus trabajos, que permitía replantear la concepción de la pintura y desafiar sus comprensiones. Sin embargo, si las obras y la actitud de Rauschenberg eran intencionalmente citadas en extenso en su ensayo, los cómics de Roy Lichtenstein eran reprobados por el crítico, debido a su sarcasmo y embaucada pretensión de "hacer arte en el sentido tradicional de la palabra" (1965, p. 276). La polémica para Romera constituía la ausencia de contenido o ideas, $\mathrm{o}$, en su defecto, la temática "chabacana y pedestre" de esas pinturas pop, que en su realismo artificial y simple reducían la narrativa de sus figuras y textos, suplantando posibles definiciones o lecturas por planos y patrones mecánicamente reproducidos. Sin considerar atributo alguno en las obras de Lichtenstein ni ofrecer mayores señales sobre su rechazo, Romera deslizaba un desprecio hacia el lenguaje del cómic por su baja calidad, y, por tanto, también la imposibilidad de incluirlo en el campo del arte.

Precisamente, la provocación de las pinturas de Lichtenstein radicaba en un juego con la narrativa, la composición y el color de la tira cómica y la ilustración publicitaria al descontextualizar la historia, maximizar los primeros planos de las figuras u objetos, exagerar artificialmente sus estereotipos y construcciones (colores primarios y planos, bordes gruesos, negros y contras tados) y emplear los clichés de las emociones en torno al amor y la guerra, principalmente mediante la representación de la miserable tristeza de mujeres
${ }^{2}$ El crítico de arte publicó Asedio a la pintura chilena en 1969, el primer libro que trataría la coherencia de temas y grupos artísticos del género pictórico desde el enfoque de la "materia creadora" y la "depuración formal". Uno de los últimos colectivos en incluir en su libro fue el Grupo Rectángulo, al cual destacó por ser "el primer movimiento constructivo" y por cumplir en 1965 una década de vida desde su fundación. Atribuyó al grupo, como reacción contra la pintura expresiva, informalista y caótica, la propuesta de una pintura abocada al control de las sensaciones y a la "frialdad asentimental". En su libro, Romera no incorporaría las obras de artistas chilenos jóvenes que tuvieran cercanías con el pop. 
esperando o la expresión de miedo de pilotos de avión en el momento de estrellar al enemigo. Aun con el drama de esas pinturas, la técnica comercial y el estilo esquemático de producción como máquina industrial vaciaban un posible espesor emotivo transformando aquellas escenas en ficción popular o incidentes fantásticos.

Defendido por algunos, pero sobre todo interpelado por muchos críticos norteamericanos, quienes dudaban de que sus piezas pudieran ser consideradas arte, Lichtenstein, así como su actitud y sus obras, generó varias controversias en la prensa. Se publicaron reseñas de su trabajo bajo títulos cargados de hostilidad, como “¿Es el peor artista en Estados Unidos?” (Seiberling, 1964, pp. 79-83), y constantemente se repetía el cuestionamiento de si su obra constituía una burla para los amantes del arte por su falta de imaginación, poesía y misterio artístico. En ese conjunto de frases desafortunadas para el trabajo de Lichtenstein, las críticas que apuntaba Romera no eran disparatadas. Más bien, dejaban entrever una posición alineada al disgusto común entre aquellos críticos defensores de un orden modernista que observaban una división excluyente entre la cultura de masas y el arte, o entre la baja y la alta cultura. Como señaló la crítica de arte Lucy Lippard (1966, p. 9), "la indignación estuvo acompañada de una profunda decepción por parte de muchos artistas y críticos” en Inglaterra, Estados Unidos y Europa. Visto desde la independencia respecto de la naturaleza que algunas doctrinas del arte moderno transmitían (Baudelaire, 1859), este arte fuera de lo solemne abría nuevamente un camino hacia todos los accidentes y deformaciones de la realidad.

En lo que refiere a las prácticas artísticas chilenas de impronta pop, la descalificación de los críticos locales fue aún mayor. A diferencia de Nueva York, allí no existía una apertura del debate y las discrepancias entre críticos, ni tampoco un mercado de dealers y coleccionistas influyentes que pudieran contribuir a la comercialización de las obras. Así, en sus distintas formulaciones, los artistas Francisco Brugnoli (1935), Valentina Cruz (1938), Virginia Errázuriz (1941), Guillermo Núñez (1930), Juan Pablo Langlois (1936) y, posteriormente, Cecilia Vicuña (1948) recibieron el malestar de la crítica ante la aparición de sus obras y exposiciones.

Fuera de los parámetros correctos, académicos o del buen gusto, los artistas movilizaron inquietudes y cuestionamientos con una actitud de libertad y abierta experimentación en los agitados años sesenta en Chile. Sus referencias convivieron con la cultura de masas de Estados Unidos, ya fuera al viajar, residir temporalmente y producir algunas obras en Nueva York o al obtener e informarse a partir de revistas extranjeras de arte, música y cultura. Sus trabajos eran, por una parte, una extraña combinación de la estética vulgar 
emparentada con los trabajos de Rauschenberg con la estética pobre de la calle y el campo, la mala habilidad técnica y el pegoteo de desechos u objetos de procedencia local y en estado ruinoso. Por otra parte, en su estado más pulcro y limpio, expresaron, a contracorriente del brillo y el glamour norteamericanos, una crítica y denuncia frente a las inequidades sociales, las muertes producidas por la industria bélica y tecnológica, la propagación de estereotipos y la resistencia a los comportamientos ideologizados. Constituían un imaginario "poplítico" — como el propio Núñez se autodefinió en los años sesenta (Ossa, 1966) —; una vertiente en la cual las obras apuntaron directamente a la violencia de la calle y a una interpelación frente a las injusticias sociales y políticas. En un ámbito filosófico, visibilizaron el desmoronamiento de los valores del ser humano y el decaimiento de un humanismo que se veía amenazado por la abundante supertécnica y el consumo, o, en sus efectos, por la dominante indiferencia social.

Mientras los jóvenes artistas se apropiaron de objetos, de medios masivos o del arraigo popular con una actitud provocativa, los críticos asediaron esta "amenaza" buscando, por un lado, resistir el decaimiento del pensamiento humanista y la velocidad de los cambios del arte contemporáneo, con la insistencia de mantener los valores metafísicos del arte moderno, y, por el otro, invalidaron públicamente su existencia mediante la publicación y circulación de reseñas que desacreditaban sus obras.

En el primer caso, a contrapelo del viraje artístico y la agitación de las reformas sociales que se estaban gestando en Chile y Latinoamérica, la crítica conservadora solicitó una "función mayéutica" para el arte, es decir, que el arte fuera "proyectivo, alumbrador y adivinatorio de aquellas tierras incógnitas, sobrantes y oscuras" (Oyarzún, 1969, p. 17). De alguna manera, los alcances de la abstracción, en particular aquella vertiente expresiva y vitalista que podría reconocerse en el lenguaje de las esculturas de inspiración ancestral e indoamericana de la artista Marta Colvin (1907-1995), canalizaban una integración entre las fuerzas enigmáticas de la naturaleza, el macizo andino y las culturas milenarias y el empleo de una materialidad vernácula al utilizar fielmente materiales nobles como la madera y la piedra (García, 2015). Residente en París, Colvin constituyó para la crítica un referente sobre las exploraciones del arte abstracto, sobre todo al obtener el Primer Premio de Escultura en la Bienal de São Paulo en 1965 y encumbrarse hacia una "inscripción internacional” (Mellado, 2015, p. 51). El mismo premio podría leerse como una adscripción a la tradición de las escuelas francesa (Ossip Zadkine) e inglesa (Henry Moore) que Colvin conoció en sus años de formación, a lo largo de los años cincuenta, y que integró durante los años sesenta. 


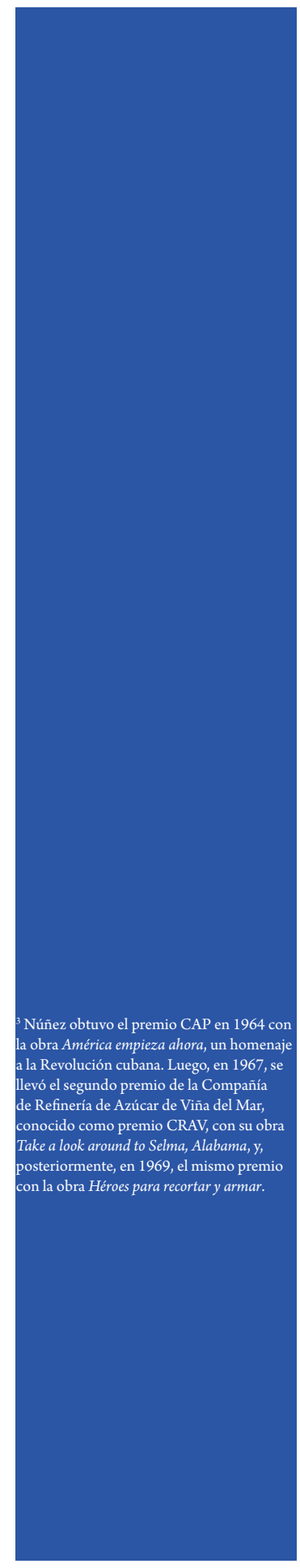

En el segundo caso, los críticos reconocieron que los artistas jóvenes chilenos sintonizaban con las transformaciones del arte contemporáneo; sin embargo, no dejaron de reparar en la actitud destructiva de sus trabajos. Si Romera (1965, p. 1) los calificaba de "arte populachero" y Ana Helfant (1967, p. 31), de "arte pesadilla", otros críticos fundamentaban lo absurdo de su existencia al no haber surgido de "raíces profundas de la cultura de masas de un país industrializado” (Anón., 1967, p.25). Encasillada como un arte de "segunda mano", la vertiente pop en Chile se percibió como una usurpación extranjera sin derecho a existir.

Fuera de la institucionalidad museística y en oposición a un movimiento articulado, la "admisión” de las piezas con carácter pop sucedió a través de la irrupción de estos trabajos en eventos extraoficiales a la formación académica, esto es, en festivales, ferias, concursos, exposiciones al aire libre o en galerías y espacios privados. Por ejemplo, las obras de los artistas Francisco Brugnoli y Virginia Errázuriz, quienes fueron integrantes del grupo Los Diablos, irrumpieron en la VII Feria de Artes Plásticas, realizada en el Parque Forestal de Santiago en 1965, y desataron, según la crítica, la furia de algunos asistentes, que reclamaron el retiro de sus trabajos por la ofensa de los pegotes en estructuras sucias, por los tapices hechizos de comentario político o por la demostración obscena de ropa interior colgada (Lago, 1965). Las pinturas de Guillermo Núñez y las esculturas de Valentina Cruz se exhibieron en la galería El Patio (en 1965 y en 1968, respectivamente) luego del replanteamiento formal y material de la producción de sus obras tras su estadía en la ciudad de Nueva York. Núñez participó en concursos auspiciados por empresas privadas y obtuvo algunos premios, gracias a los cuales la sede de la Quinta Normal del Museo de Arte Contemporáneo (MAC) de Santiago y el Museo Nacional de Bellas Artes accedieron a exponer su trabajo ${ }^{3}$. Las obras presentadas eran pinturas que, apropiándose de noticas sobre la guerra de Vietnam o de pugnas contra las minorías raciales y obreras, tramaban el dolor con colores envolventes. El artista exhibió en varios festivales, como el Festival de Pintura Americana en Lima, Perú, y en exposiciones al aire libre en sectores marginales de la ciudad de Santiago, como la muestra "Vietnam Agresión” (1967), en la comuna de San Miguel. Aun cuando sus telas no estuvieron libres de algunos altercados polémicos al ser descolgadas, laceradas y destruidas, el artista gozó de una mayor aceptación por parte de la crítica (Romera, 1969) que otros de sus contemporáneos, cuyas obras despertaron en ella altas dosis de desprecio.

En ese sentido, Valentina Cruz fue una de las artistas más severamente criticada. En 1965, el mismo año en el que Colvin fue reconocida en la Bienal de São Paulo, Cruz obtuvo el Primer Premio de Escultura en la IV Bienal Internacio- 
nal de Arte Joven de París con su obra Hombre de pie. Sin embargo, al momento de regresar y exhibir en la Bienal de Escultura en Santiago (MAC, 1967) o en una de sus primeras exposiciones individuales en la galería El Patio (1968), fue reprochada por "demoler" los ideales sobre la capacidad plástica, desatender el talento artístico y perder los equilibrios, los valores de la creación y los sentidos humanos. Parafraseando a la crítica Ana Helfant, Cruz trataba con su obra de "hacer un antiarte" que se arrastraba hacia objetivos negativos mediante la representación de la crisis acaecida en aquella época al fallar los valores modernos del arte (1967, pp. 22-23). Mientras que Helfant consideraba que la obra de Cruz destruía los valores artísticos y que el talento de la artista era una engañosa construcción de los medios internacionales tras la obtención de su premio en París, la propia artista atendía justamente a las fallas, ineficiencias, destrucciones y vaciamientos de la materia corporal del ser humano que surgieron cuando este fue remplazado por las máquinas y, por tanto, minimizado al grado cuántico: una cosa, un producto, un número más. Como se comentará más adelante, las esculturas de Cruz, hechas de pieles metálicas moldeadas con goma látex a partir de su propio cuerpo, componían gabinetes, botiquines, paquetes y máscaras, que evocaban un laboratorio portátil abastecido de matrices de seres humanos, instrumentos científicos y asépticos.

\section{El estado marginal del arte pop en Chile}

Si bien la crítica de arte en Chile en los años sesenta contó con una distribución en el campo universitario y en los soportes de prensa escrita ${ }^{4}$, autores actuales le han atribuido a sus expresiones una actitud negativa, determinada por los "juicios lapidarios" tanto hacia el arte abstracto como el figurativo (Galaz e Ivelic, 1988, p.70), y un aislamiento respecto de los debates latinoamericanistas del momento (Mellado, 2015). Sin embargo, han sido escasos los reconocimientos en la actualidad sobre el carácter de las obras de los artistas y el contexto que motivó la rebeldía juvenil y la experimentación. Aunque son varias las razones que informan del estado marginal en el que se han mantenido estas prácticas hasta la fecha, dos de ellas destacan especialmente por la trascendencia del eclipse de sus formas.

La primera, ya comentada y más evidente, constituyó aquel apernado ejercicio por parte de la crítica de defender el canon del arte moderno europeo. Esta tradición no daba cabida al relato de los conflictos sociales, el cual, sin embargo, animaba a los artistas a volcarse en las revueltas en Latinoamérica, por ejemplo, en los enfrentamientos populares y callejeros que tuvieron lugar desde fines de los años cincuenta en Santiago (Salazar, 2006). Asimismo, las consignas e invocaciones prerrevolucionarias fueron una fuerza vital luego del triunfo de la

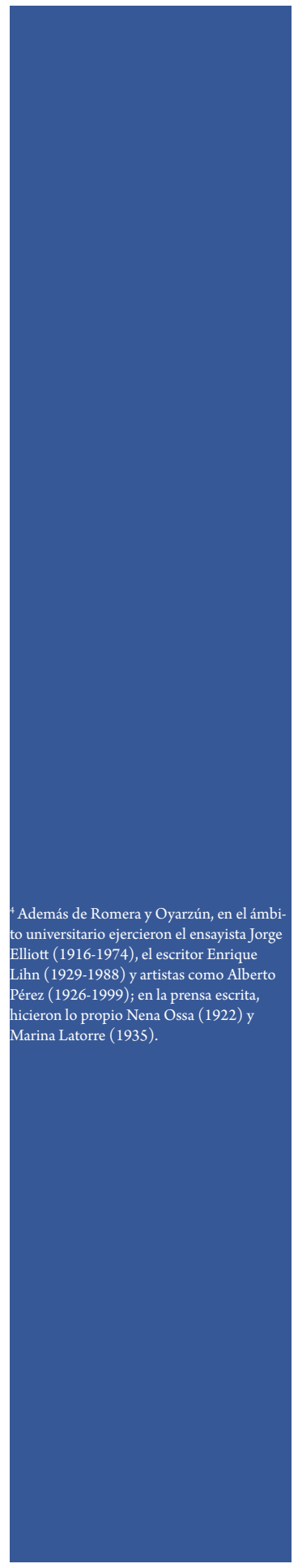


Revolución cubana y el forcejeo a nive mundial que las ideologías comunistas y capitalistas enfrentaron geopolíticamente para posicionar sus obras.

Al igual que muchos países latinoamericanos, Chile vivió una modernización económica acelerada que buscaba incrementar la productividad agrícola, las exportaciones, la profesionalización y la condición salarial en las industrias mediante dos pilares estructurales: la reforma agraria en 1962 y la universitaria en 1968. En ese proceso transformador, la modernización en el campo universitario condujo a una serie de pugnas en la Facultad de Bellas Artes de la Universidad de Chile, donde a inicios de los años sesenta una fracción de académicos y estudiantes apelaron a una formación y una vocación de los artistas más estrechas con los problemas de la vida social y al servicio del pueblo, así como al compromiso político, a la denuncia y al trabajo junto a los más explotados, en vez de a un perfil académico subordinado a los intereses corporativos de la educación, las industrias y el bienestar de la sociedad (García, 2018).

Este ánimo estimuló una inmersión en la realidad y la creación de obras con un auténtico rostro local o latinoamericano. Los artistas expresaron su inconformismo frente a las jerarquías y doctrinas de la tradición modernizadora de las Bellas Artes, reaccionaron contra el culto burgués de la pintura de caballete y la utilización de materiales nobles para la escultura, y los remplazaron por materiales industriales, por el uso de reproducciones de los medios de masas tanto nacionales como internacionales, por una arqueología del desecho y sus metáforas de la pobreza, por la obtención y circulación fácil y barata del cartel o afiche. Esta producción artística de mediados de los sesenta cobró vigor y fuerza durante las campañas del Frente de Acción Popular (FRAP), y se intensificó aún más con el advenimiento de la Unidad Popular y el gobierno socialista y democrático de Salvador Allende entre los años 1970 y 1973. Si bien existió una posición política de los artistas más cercana a la izquierda, su adhesión tendió hacia una militancia social; un apoyo moral y activo más que una retórica dogmática e ilustrativa de los partidos.

La segunda razón que explica la desaparición de los rastros del arte pop en Chile constituye la borradura y autocensura historiográfica y teórica tras el golpe de Estado de 1973 y su extensa duración hasta 1990, que obligó al silencio de temáticas revolucionarias y de las acciones políticamente comprometidas de muchos artistas. En el trascurso de los primeros años de la dictadura militar, los artistas opositores al régimen fueron exonerados de sus cargos universitarios (Brugnoli y Errázuriz), torturados y forzados al exilio en el extranjero (Núñez), o se refugiaron en un autoexilio físico o interior tanto en Chile como en otras partes del mundo (Cruz). Al distanciamiento geográ- 
fico y físico de los artistas se unió el alejamiento y la privación del arte de los discursos de la realidad social. En el intersticio de los años setenta y ochenta, prevaleció un arte recluido al mundo privado (museos, galerías y universidades), con esporádicas intervenciones de colectivos artísticos en la calle. Con un lenguaje basado en los signos y envuelto en lecturas conceptuales, se instaló el discurso de la "avanzada" o un itinerario "no oficial" del arte a partir de la publicación de Nelly Richard Margins and Institutions, en el journal Art \& Text publicado en 1986. Tal como señala Polgovsky (2014, p. 135), en este discurso existió un "desplazamiento de filiaciones estéticas y metafísicas" para dar énfasis a una lectura desde un lenguaje semiótico a un conjunto de obras de artistas, entre las que se incluyeron las de Eugenio Dittborn y Carlos Leppe, cuyas exploraciones se abocaron a las brutalidades y el trauma de las desapariciones en los tiempos del régimen, a los signos de las huellas, a los soportes técnicos y los procesos materiales, y a la impronta de los cuerpos desde los cruces de la gráfica, la fotografía, el vídeo, la instalación y la performance.

El poder de ese discurso y de las prácticas artísticas después de 1973 tuvo un legado en la formación artística e historiográfica desde los años noventa hasta la fecha, lo que desembocó en el olvido de aquellas convicciones y revueltas que exaltaron con color y mensajes directos los conflictos artísticos y sociales de la larga década de los años sesenta (1960-1973). Cubiertos por una tabula rasa histórica, se podría conjeturar que existió rechazo e incomodidad por atender $y$ abrir aquellas viejas discusiones que quedaron hechas pedazos con el golpe. Frente a esa desmemoria voluntaria o inconsciente de los relatos, se busca recuperar algunos de esos restos pop que han sobrevivido en las obras y relatos de los artistas; en sus posiciones, actitudes y preguntas. Así, las siguientes líneas intentan explorar a modo de síntesis algunas de las piezas realizadas por los artistas Francisco Brugnoli, Virginia Errázuriz, Guillermo Núñez y Valentina Cruz en la segunda mitad de los años sesenta, previamente al gobierno de la Unidad Popular, con el fin de acercar la distancia temporal de estas obras relegadas, estableciendo el horizonte social que cruza el arte pop con un imaginario popular y político.

\section{Del imaginario popular del pop a las políticas del cuerpo}

En un ambiente político altamente polarizado y socialmente efervescente para los jóvenes artistas, aparecen las primeras incursiones del pop en la VII Feria de Artes Plásticas en el Parque Forestal. Francisco Brugnoli y Virginia Errázuriz, ambos estudiantes de la especialidad de Pintura en la Facultad de Bellas Artes de la Universidad de Chile, presentaron sus "pegoteados" y "tapices", respectivamente, y, con ellos, generaron la indignación en el público y los 


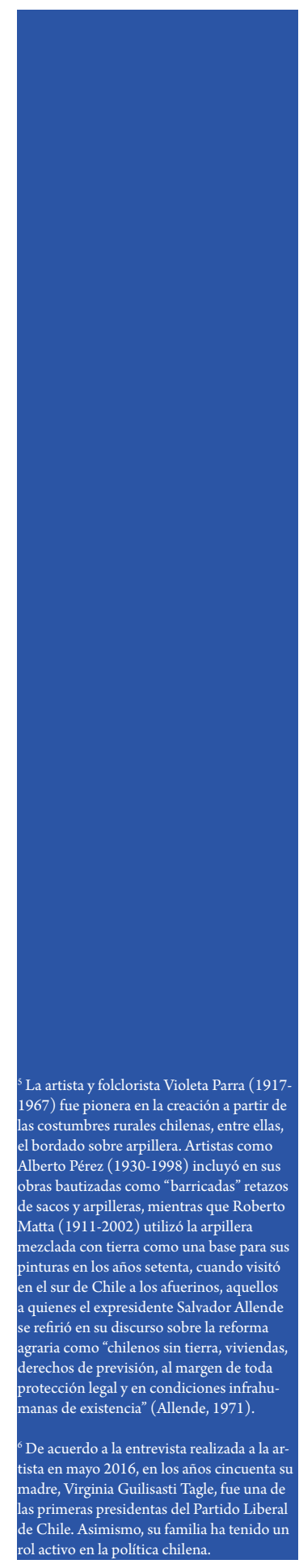

medios de prensa. Las obras despertaron un total desconcierto por la utilización directa de desechos y residuos encontrados en la calle, como sucedía en las piezas No se confíe, de Brugnoli, y Sin título, de Errázuriz, ambas de 1965. La nueva anatomía de sus trabajos se componía de la defectuosa aplicación de pintura o costura sobre retazos de telas rotas o tableros de madera encontrados y de la unión de un sinnúmero de plásticos, bolsas y recortes de la prensa: una intersección de collages fuera de regla y un montaje de objetos en estado de ruina con una potencia viva y un discurso ácido sobre las contingencias locales que afectaban colectivamente.

El empleo de arpilleras, sacos y trapos de telas en las piezas de Errázuriz emergió desde la cotidianeidad familiar, el imaginario doméstico y de la recolección de objetos o desperdicios de la calle: el nuevo paisaje urbano provisto de información publicitaria y comercial. Los tapices — como los llamaría la artista - representaban un conjunto de personajes y rostros populares anónimos, cercanos o familiares a ella, como Mi tía lánguida (1966, fig. 1) o El Goyito (1967, fig. 2), y estaban compuestos de restos de géneros, lanas, pantis y objetos destruidos y en desuso que, al ser hilvanados y unidos, lucían en general una distorsión graciosa y sarcástica del cuerpo femenino y masculino. La agudeza manual y estética se encuentra en las expresiones de los rostros, en el arreglo de las vestimentas o en una descripción de las topografías interiores del cuerpo por medio de las superposiciones de trapos.

Usualmente, en la historia han existido varias metáforas y mitos en torno a los usos de las telas, los hilos y los géneros en el textil en relación con la precariedad de la existencia humana, a sus asociaciones a un oficio menor asignado a tareas femeninas, a las reparaciones de los estados de violencia, a las presencias inmateriales y fantasmagóricas de la memoria, entre otros. En el caso de las semánticas sobre los sacos, trapos y arpilleras, las metáforas rondan en la pobreza del material como un signo alegórico de las representaciones de lo popular, lo propio, o de las carencias y los harapos de los más marginados. En el Chile de los sesenta, el uso de sacos y arpilleras se transformó en un emblema artístico para dar cuenta del pueblo y la revolución ${ }^{5}$.

En el caso de las obras de Errázuriz, sus tapices y objetos excedieron los límites tradicionales designados al textil para desarropar tabúes sobre el género, sus estereotipos impuestos en el hogar, en el arte, en la moda y en la sociedad en general. Proveniente de una familia de clase alta y de un ambiente animado por la discusión política ${ }^{6}$, la artista creó unos tapices e instalaciones que, como los accesorios que aplicó en ellos (parquet y timbres de madera), surgían, entre otros, del propio espacio y pasatiempo de su círculo familiar. Los decorados de una casa burguesa y las manualidades de bordado conce- 


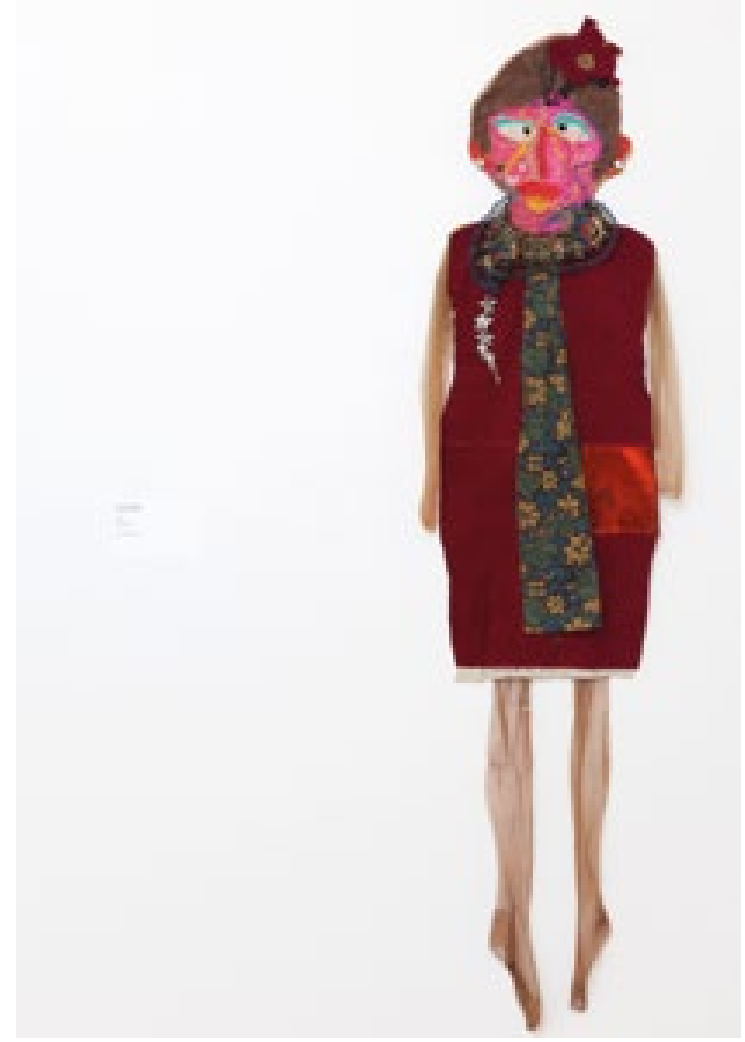

Fig. 1. Errázuriz, V., 1966. Mi tía lánguida. [tapiz, fotografiado por L. González] (Santiago de Chile, colección particular).

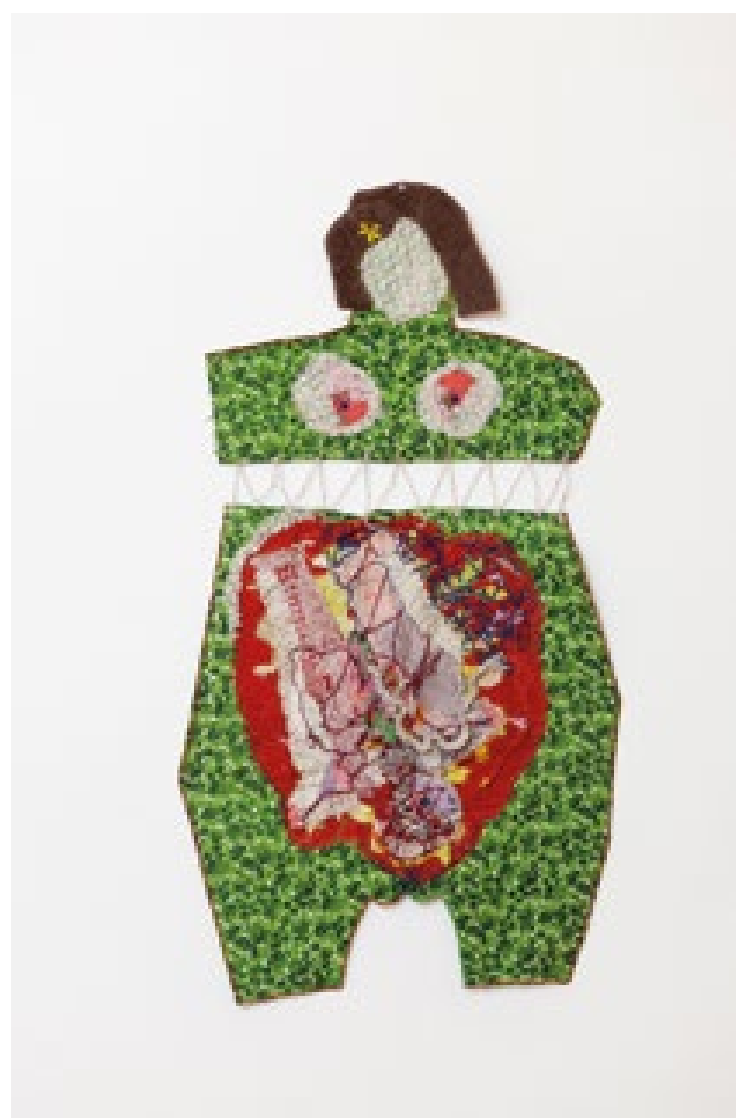

fig. 2. Errázuriz, V., 1967. El Goyito. [tapiz, fotografiado por L. González] (Santiago de Chile, colección particular). 
Tanto Errázuriz como Brugnoli apoyaban as transformaciones sociales, principalmente la emancipación de los trabajadores que vivía el país, a través de sus exposiciones e intervenciones desde su participación en el Frente de Acción Popular.

Tal como señala Josefina de la Maza en su bro De obras maestras y mamarrachos, el érmino "mamarracho", en su uso coloquial n Chile, refiere a "una persona o un objeto extravagante, desaliñado o imperfecto" (2014, p. 23).

didas usualmente a una mujer de su tiempo y posición fueron destrozados y recompuestos físicamente. El resultado, a contracorriente de lo aceptado, fue un acabado de piezas cuyas terminaciones eran defectuosas, deshilachadas e incompletas. El énfasis en el oficio incorrecto y la mala habilidad técnica en Errázuriz pueden interpretarse como una autodeterminación por diluir las fronteras que separan los ambientes de la élite y las lógicas del arte con respecto a las masas, sobre todo si se considera la sensibilidad comprometida y creativa de los artistas por estrechar lazos con la realidad y su adherencia activa en la militancia social ${ }^{7}$.

Al desafío de eliminar esas fronteras entre el arte y la vida se suman las estructuras pedagógicas de la institucionalidad del arte. En los años sesenta, comprender los tapices de Errázuriz como pinturas significaba descomponer el modelo pictórico de la ilusión, su naturaleza estática, su composición verosímil, su recepción centrada en la contemplación. Significaba, en retrospectiva, desechar y quebrar un monopolio artístico y patriarcal de las convenciones de la pintura. Si bien Errázuriz contaba con una formación universitaria tanto en la pintura como en la gráfica, sus tapices se volcaban hacia los materiales propios de los oficios de la artesanía (arpillera) y el diseño textil (la costura manual de telas). Una de sus piezas que demuestran la mezcla de lenguajes artísticos y artesanales es el tapiz Sin título, de 1965, el mismo que generó aquel escándalo en la Feria de Artes Plásticas (fig. 3). La expresividad de este retrato anónimo adquiere varios rasgos y significados sobre el imaginario popular en el contexto de las desigualdades sociales que, de acuerdo a la artista, se encubrían a favor de los progresos económicos. La trama del sujeto popular fue retratada por Errázuriz sin exaltación ni singularidad individual: más bien compuso un rostro genérico que fluctuaba entre máscara y mamarracho $^{8}$, y cuyas expresividades se basan en una "piel" de arpillera, esto es, en un aspecto mestizo de la piel, además de en un variado uso de trozos de telas de colores rosados y celestes superpuestas por medio del hilván y que dan a conocer la personalidad interior de un retratado pobre. En la frente del personaje se encuentran adosados a la arpillera un pequeño envase plástico de pastillas y parches que parecen delimitar la herida provocada por el ataque simbólico de un pequeño avión celeste de juguete, situado sobre la imagen del expresidente Eduardo Frei Montalva (hoy desaparecida).

Las indicaciones directas en contra de Frei Montalva ya habían sido utilizadas por la artista en la pintura-valla-defensa 2, 2, 2, de 1964 (fig. 4), donde materializó la amenaza ideológica de la candidatura del que fuera presidente entre 1964 y 1970 mediante un ensamblaje triangular de listones de madera sobre los cuales incorporó pintura roja y textos como "peligro", "222" o "Frei Frei". Los números aludían al registro electoral de Frei, quien, siendo representante 


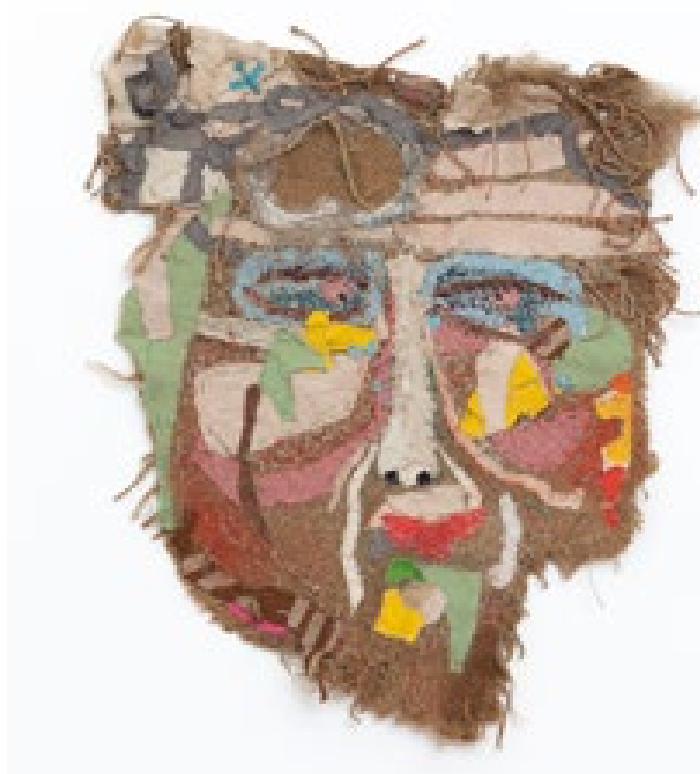

fig. 3. Errázuriz, V., 1965. Sin título. [tapiz, fotografiado por L. González] (Santiago de Chile, colección particular).

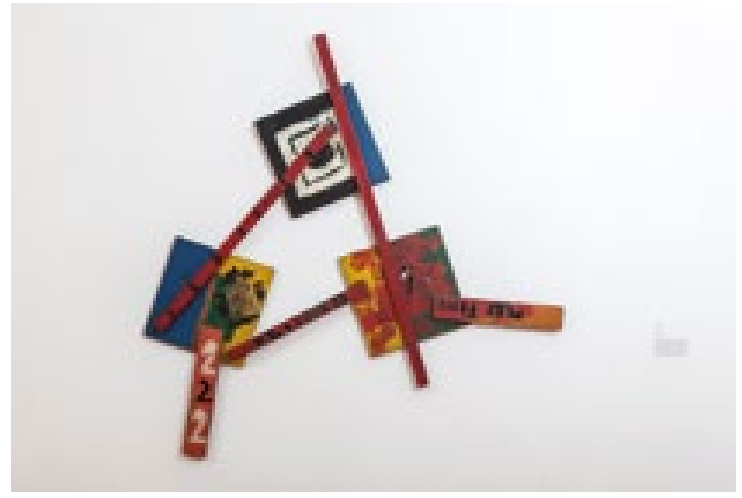

fig. 4. Errázuriz, V., 1964. 2, 2, 2. [pintura-valla-defensa, fotografiada por L. González] (Santiago de Chile, colección particular). 
del Partido Demócrata Cristiano, disputó la candidatura presidencial, entre otros, con Salvador Allende, candidato de la coalición de partidos de izquierda, el FRAP. En medio de la campaña conservadora y anticomunista de Frei Montalva, conocida como la "campaña del terror”, Errázuriz realizó 2, 2, 2 en los últimos años de sus estudios en la Escuela de Bellas Artes, con el objetivo de denunciar la agresividad política del programa de Frei Montalva. El peligro que observó Errázuriz era el control social de las masas populares a través de un Gobierno con interés empresarial que se camuflaba en un Estado democrático.

De esta manera, el imaginario popular del pop en Chile se podría ubicar en oposición a la afirmación y el gusto de una cultura artificial y mediática de la cultura de masas —encontrados, por ejemplo, en las pinturas de Lichtenstein - para, más bien, apropiarse y alterar ese universo de fantasías sociales, políticas y económicas a modo de antídoto con el que desconfiar, remecer y denunciar los espejismos que los nuevos objetos de consumo comenzaban a encantar. En esa misma línea y desde una perspectiva humanista, anticolonial y en medio de las reivindicaciones de las masas postergadas, existieron debates por parte de los artistas sobre los adoctrinamientos que el pop art norteamericano inculcaba. Para el artista e historiador del arte de izquierda Alberto Pérez (1970, p. 15), la propagación de las obras de artistas como Jasper Johns, Claes Oldenburg, Andy Warhol y Rauschenberg encarnó y ejercitó "la destrucción del hombre". Contrario al valor de los objetos de plástico que producía e importaba la industria moderna de Estados Unidos, Pérez (1970, p. 14) observaba en las obras de esos artistas "el elogio al enanismo del hombre”, es decir, una extrema valorización al gran tamaño de los envases de Coca-Cola, conos de helados o chicles que, en su magnitud, generaban una insignificancia humana. Esta sobreabundancia material y escala monumental de las obras propiciaría un debate que diferenciaría las resonancias y la validez del arte pop en otras ciudades del mundo, y no solo en América Latina, sino también en Inglaterra y Europa en general.

Asimismo, si las esculturas colosales, de plástico y colores estridentes de Oldenburg conjugaban un ambiente inerte de comida y objetos hogareños (Crow, 2014), en Chile, las obras objetuales del artista Francisco Brugnoli se abocaron a intensificar el componente humano a través de las condiciones publicitarias de los alimentos importados y su brecha con la pobreza infantil o las purgas de restos de plásticos como excrementos expulsados y reventados a partir de la confección de cuerpos. Obras como Los alimentos (1965) acercaban al espectador a observar un collage donde confluían los lados opuestos del deseo: la cotidianeidad atractiva de la comida y una constante repetición de fotografías de niños pobres. La mayoría de sus trabajos de los años sesenta corresponden a instalaciones saturadas de objetos inútiles y sucios; una pro- 
testa y advertencia sobre las causas de muertes producidas de manera no natural, es decir, muertes producidas por accidentes, enfermedades y pobreza, a partir de la fantasía y la posesión insaciable de objetos de consumo: bicicletas, autos, envases de medicamentos y alimentos.

Una de las características que une a los autodenominados "pegoteados" de Brugnoli es la centralidad que adquiere en cada uno de sus trabajos - No se confíe (1965) o Siempre gana público (1966, fig. 5), entre otros- el hombre invisible y solo. A partir de overoles y mamelucos, Brugnoli instalaba un bulto de ropa abierto o reventado desde donde sobresalían los despojos de plásticos, semejantes a trozos desperdigados de una columna vertebral. Como explicó Brugnoli (1989, p. 8), sus obras y las de Errázuriz provocaron un horror al momento de mostrase, pues en ellas quedaban expuestos "el desparpajo y la exhibición brutal de materiales de desechos — la recolección de los tesoros de una sociedad en vías industriales, en la cual se atesoran envases de yogur, cajas de huevos, envases de medicamentos-; todos objetos cuya posesión maravillaba por la señal de participación en el mundo de bienestar que anunciaban”.

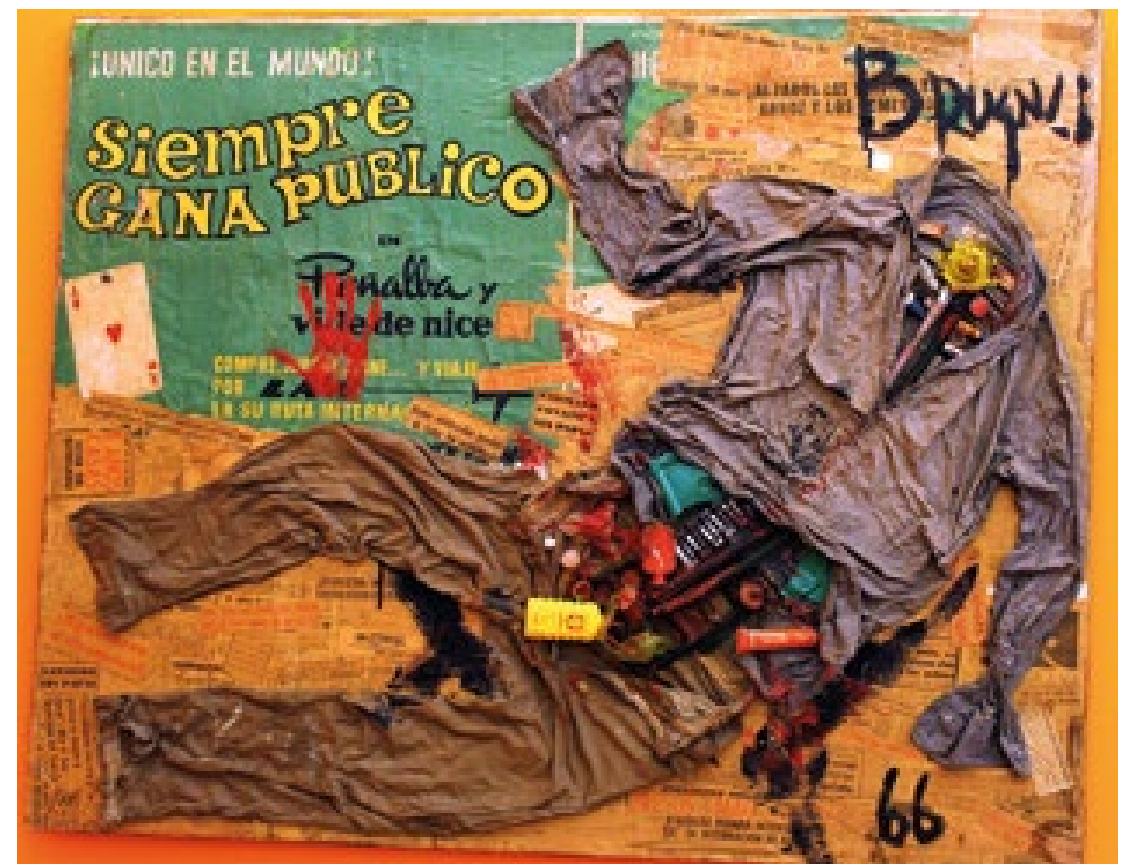

Fig. 5. Brugnoli, F., 1966. Siempre gana público. ["pegoteado", fotografiado por L. González] (Santiago de Chile, Museo de Arte Contemporáneo Universidad de Chile). 
En los años sesenta, la denominada Alianz para el Progreso convocó concursos en América Latina y dio un gran impulso al Departamento de Artes Visuales de la OEA on oficina en Washington. Por otro lado, el nfoque más cercano a lo estadounidense o representó el cubano José Gómez Sicre, uncionario de la OEA y director del antigu Museo de Arte Panamericano. Según el profesor Ramírez Nieto, desde el norte se modeló un concepto unilateral sobre lo que debía ser lo latinoamericano y el prototipo de arte que se debía producir.

${ }^{0}$ En esos momentos, los artistas que se ncontraban en Nueva York eran Eduardo Martínez Bonati, Carlos Ortúzar, Juan Downey, Iván Vial, Sergio Castillo, Enrique Castro-Cid, Juan Gómez Quiroz y, en casiones, Roberto Matta.
La conmoción frente a la muerte y la desaparición de una identidad individual y colectiva que se repetía diariamente constituían un escudo de resistencia y contención por parte de los artistas en Chile a la hora de reconciliar la realidad con el arte. En otro contexto geográfico y abiertamente publicitario, la obra y la actitud de Warhol y, en particular, su fabricación "impersonal y desagradable de América" en la serie Death and Disaster ("Muertes y desastres") reafirmaban las sensaciones de indiferencia al retratar con un desapasionado tratamiento a celebridades como Marilyn Monroe, Elvis Presley o Jackie Kennedy. Lo que para Warhol (1963, pp. 103-104) eran hechos que promovían una máquina de producción en la que el tiempo, la muerte y la historia eran consumibles, para los artistas latinoamericanos eran nauseas de incomprensión, inconformismo y contestación.

Similares fueron las reacciones de los artistas Guillermo Núñez y Valentina Cruz, quienes coincidieron durante una estadía en Nueva York. Núñez, de 35 años y pintor, decidió viajar a Estados Unidos motivado por la presentación que realizó en Santiago José Gómez Sicre, jefe del Departamento de Artes Visuales de la Organización de los Estados Americanos (OEA), en la que promovió las últimas tendencias artísticas en Nueva York 9 . Cruz, de 25 años y escultora, visitó a su hermana, empleada de las Naciones Unidas, y consiguió un taller en el sótano de una gran casa en cuyo último piso donde residió el artista Nemesio Antúnez, quien en esos momentos era agregado cultural de Chile en Estados Unidos. Nueva York fue una ciudad de contacto y reuniones entre artistas chilenos y latinoamericanos ${ }^{10}$, de nutridas visitas a galerías y museos, de reconocimiento de las calles con abundante basura, comercio, noticias en los diarios y la televisión. También fue una ciudad de inquietante trabajo monástico y experimental. Mientras que Guillermo Núñez absorbió en sus pinturas las sensaciones de destrucción, los horrores y víctimas producidos por la guerra de Vietnam y los conflictos raciales en Estados Unidos, Valentina Cruz quedó asombrada por el ambiente y el ritmo de una vida fría, inhumana, de máxima eficiencia y de trato impersonal. Cada uno generó una producción en Nueva York y un cambio material en la distribución de sus figuras, colores y motivos. Núñez, en sus pinturas testimoniales —en Diseño para la muerte de Joe (fig. 6) y El último sueño de Joe (fig. 7), por ejemplo, ambas de 1966-, se acercó a la composición de la historieta utilizando repetitivamente las mismas fotografías en blanco y negro, acentuando la intensidad y degradación de rojos y rosas para los rostros, mientras que acudió a los blancos ahuesados para las figuras más sensibles, a las que, en sus palabras, "les dolerán los colores de los lados" (1993, p.77): aquellos intensos azules, verdes y amarillos. Núñez (1993, p. 30) buscó "revivir el instante mismo de dolor junto a su representación y documento (fotografías de revistas y diarios)" con el propósito, por una parte, de retener y envolver en colores la 


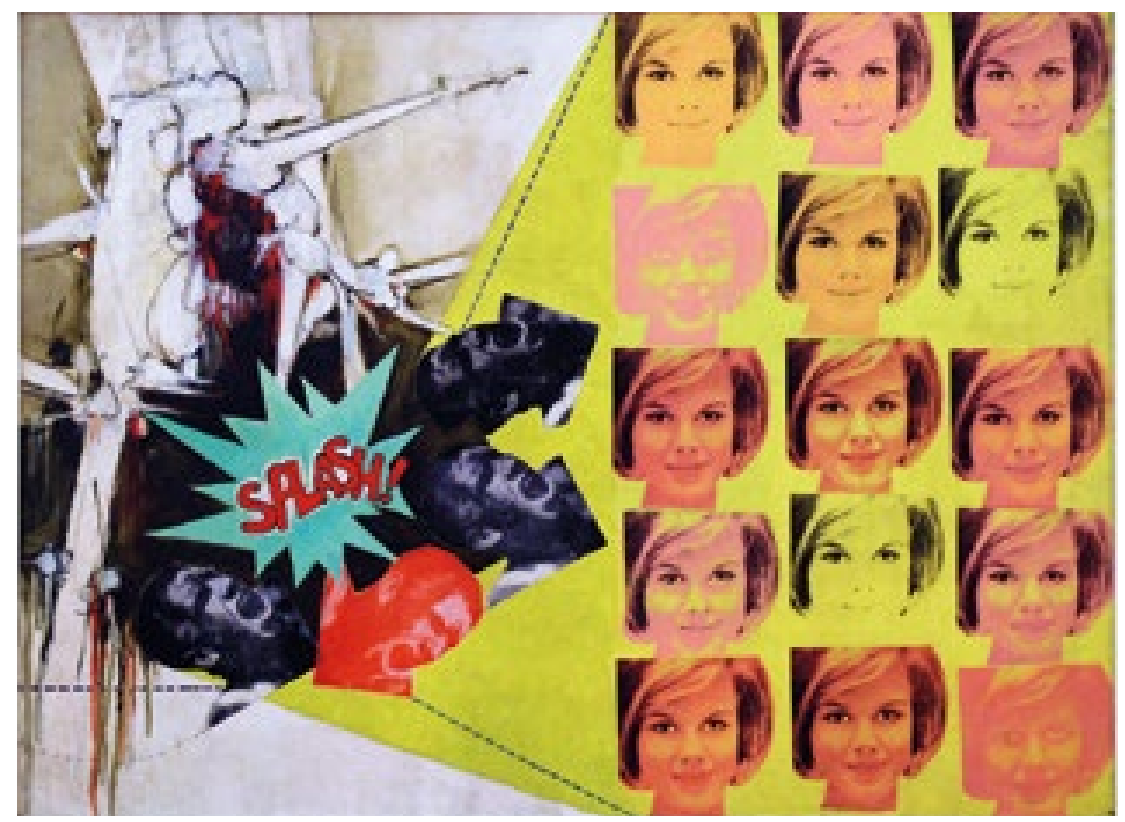

Fig. 6. Núñez, G., 1966. Diseño para la muerte de Joe. [pintura, fotografiada por L. González] (Santiago de Chile, Museo Nacional de Bellas Artes).

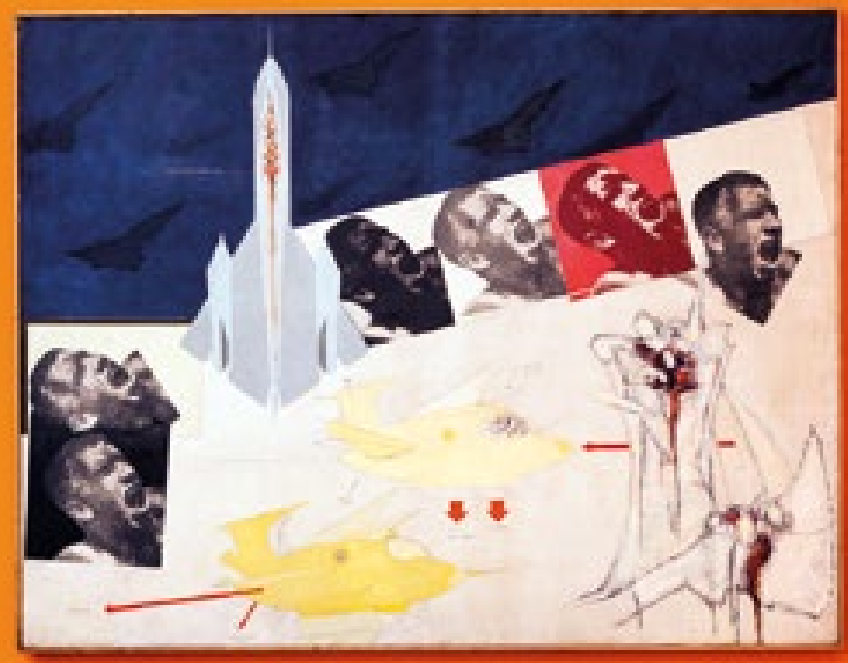

Fig. 7. Núñez, G., 1966. El último sueño de Joe. [pintura, fotografiada por L. González] (Colección David y Rita Hughes). 
mirada del observador y, por otra, de generar un distanciamiento frío sobre los impactos violentos de una víctima como Joe; un joven que, como millones de ellos, fue enviado a la guerra.

Tanto en la pintura de Núñez como en las esculturas de Cruz coexistió un interés cuidadoso por las expresiones y comportamientos de una de las cavidades más activas y conectoras entre la piel, los sonidos y las profundidades del cuerpo: la boca. La apertura desgarradora de las bocas y sus ecos congelados en las pinturas de Núñez se encontraron en los volúmenes de Cruz, en una serie de creaturas animadas y emociones encapsuladas en frascos de medicina. Como objetos de laboratorio clínico o como paquetes eficientes, sus objetos de 1966, Botiquín de primeros auxilios, Evolución de un beso, Pieles de mujeres fieles a ser examinadas por el doctor de turno (fig. 8) y Marque déposée, son repeticiones de bocas y pieles aprisionadas en frascos de vidrios y soportes metálicos que fueron aislados del ambiente natural. Cruz utilizó su propio cuerpo como matriz para moldear la goma látex y obtener una flexibilidad del material para condensar, reprimir y aplanar violentamente las formas corporales. Semejantes a las obras de Virginia Errázuriz, podemos inferir que en las de Cruz las políticas del cuerpo femenino fueron abordadas desde las divisiones laborales de género, desde su cosificación y sustitución dejando entrever, también, la piel como cadáver o como resto de un cuerpo.

Estas problemáticas surgieron de sus vivencias en Nueva York, ante el asombro que le produjo el tratamiento del ser humano como cosa, en el que las capacidades afectivas y emotivas y las sensibilidades humanas se transformaban o sucumbían en sus expresiones y aparecían, por el contrario, como unidades comparables y uniformes. Estas experiencias estuvieron, además, mezcladas por una fascinación por las nuevas tecnologías y los materiales que facilitaban la experimentación y que proporcionaban colores artificiales y planos, dando a entrever sensaciones frías. Así, obras como Marque déposée ("Marca registrada”), donde se representan extremidades del cuerpo humano — pies, manos y rostros en expresión de contorsión y asfixia-, fueron envueltas en un paquete metalizado y acordonado, asemejándose a una valija abultada de cuerpos encerrados.

La opresión de la vida del ser humano materializado en sus múltiples lugares y dominios constituyó una problemática transversal para los artistas chilenos. Ya fuera como un cuerpo popular y pobre, en las obras de Errázuriz; destruido, en el caso de Brugnoli; deshuesado, en las pinturas de Núñez, o dérmico y superficial, en las esculturas de Cruz, la inquietud de sus expresiones fragmentadas, reventadas y sofocantes daban a conocer las intensidades de un tiempo en el que la realidad destructiva de tecnologías y guerras era apropia- 


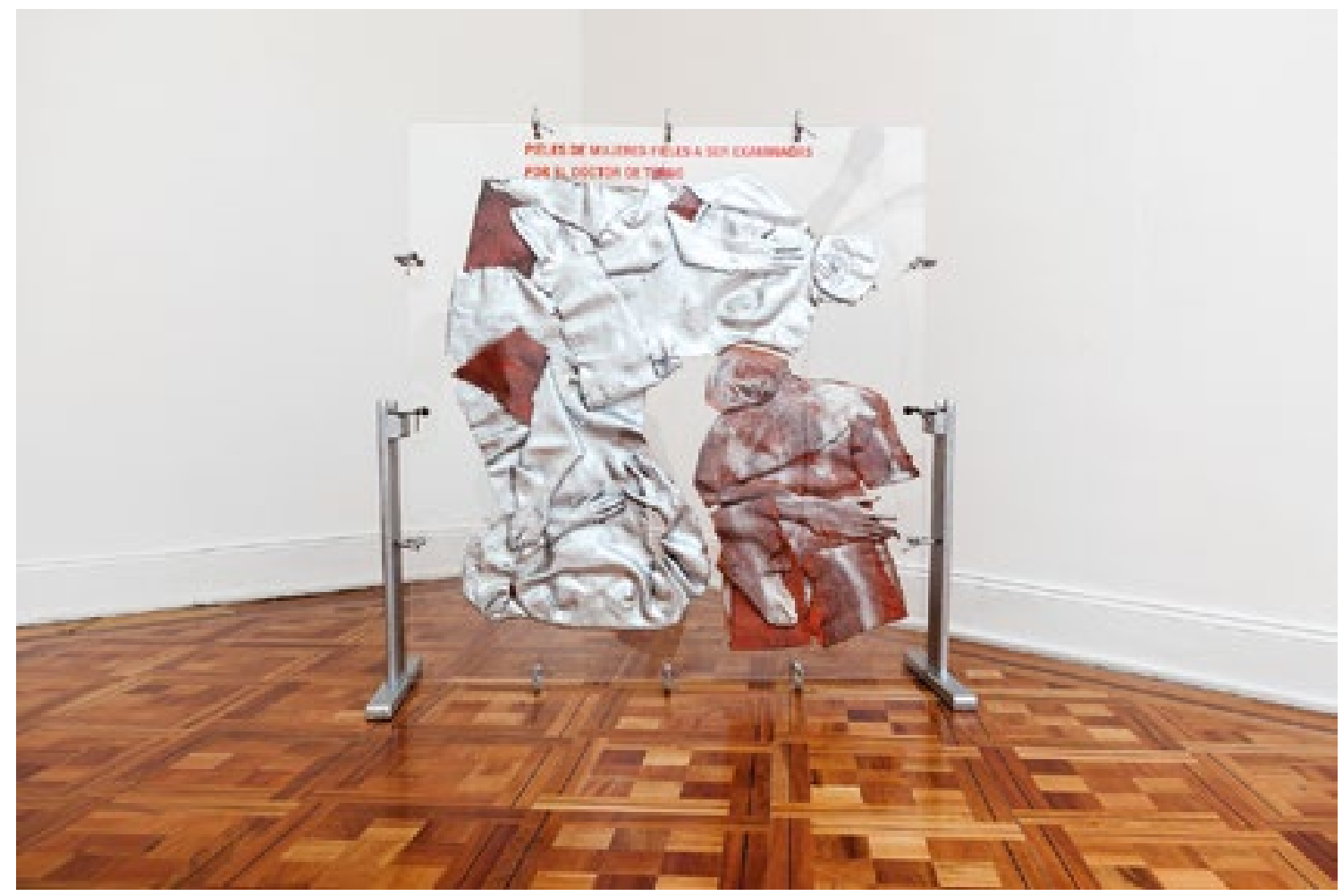

Fig. 8. Cruz, V., 1966. Pieles de mujeres fieles a ser examinadas por el doctor de turno. [escultura, fotografiada por L. González] (Santiago de Chile, Museo de la Solidaridad Salvador Allende). 
da y materializada desde la denuncia ante la catástrofe del ser humano. Las complejidades de estas problemáticas merecen ser atendidas en profundidad, sobre todo considerando preguntas en torno a los giros materiales y discursivos desde las propias agencias; las respuestas artísticas al fervor revolucionario antes y durante el gobierno de la Unidad Popular y sus derroteros luego del golpe militar.

Si bien muchos de estos artistas recibieron una atención negativa en su momento, con este texto se pretendía aportar algunas distinciones sobre las actitudes agresivas tanto de la crítica como de los artistas en la coyuntura de las luchas sociales y el statu quo del arte. Asimismo, los contrapuntos con un arte pop del norte aportaron distinciones para generar coincidencias y comparaciones con el sur: el repertorio y la circulación material de la cultura de masas proveyeron una mediación e inspiración común para los artistas, para quienes la temática de la muerte se transformó en una obsesión usual; sin embargo, sus obras abrieron direcciones opuestas. Si los artistas de la metrópolis del arte y el comercio fueron indiferentes a la interioridad de las emociones y las expresiones ( $y$, más bien, generaron una distancia a través de la reproducción y repetición de las formas obtenidas de las revistas y la televisión), los artistas del sur resistieron la extinción de las emociones y las sensaciones en tiempos en los que la empatía con la solidaridad social agitaba conexiones con el entorno real. En ambos casos, y en sus distintos contextos, las obras rompieron los moldes del arte y despertaron la furia de sus asistentes. La carencia de la aceptación de un pensamiento y práctica diferentes en Chile, además de los años de represión política durante y después de la dictadura, hizo que las historias y relatos de las obras de los años sesenta quedaran como meros espectros de una utopía incumplida. Precisamente son las rutas divergentes, apasionadas y rabiosas del arte pop en Chile las que requieren ser escuchadas para interrogar y comprender los cambios sociales que hoy nos afectan colectivamente. 


\section{Referencias}

Allende, S., 1971. Discurso sobre la propiedad agraria. [en línea] Marxists Internet Archive. Disponible en: <https://www.marxists.org/espanol/allende/1971/agosto23.htm> [Consultado el 10 de marzo de 2019].

Anónimo, 1967. Pop: arte para el hombre del sandwich en la mano. Revista Presente!, n. ${ }^{\circ}$ 6, 8 de septiembre, pp.25-26.

Baudelaire, C., 1996. Salones y otros escritos sobre arte. Madrid: Visor.

Brugnoli, F., 1989. Cirugía Plástica: Konzepte zeitgenössischer Kunst Chile 1980-1989. Berlín: Neue Gesellschaft für Bildende Kunst.

Crow, T., 2014. The long march of pop: art, music and design, 1930-1995. New Haven y Londres: Yale University Press.

De la Maza, J., 2014. De obras maestras y mamarrachos. Santiago de Chile: Ediciones Metales Pesados.

Galaz, G. e Ivelic, M., 1988. Chile, arte actual. Valparaíso: Ediciones Universitarias de Valparaíso.

García, S., 2015. Marta Colvin. Reivindicación de una presencia americana. En: J. Colvin, ed. 2015. Marta Colvin: escultora. Santiago de Chile: Bodegón Cultural de los Vilos, pp. 59-71.

García, S., 2018. Las barricadas de Alberto Pérez. Fuerzas de combate en el arte y la política. Revista de Izquierdas, [en línea] n. ${ }^{0}$ 44. Disponible en: <http://www.izquierdas.cl/images/pdf/2018/n44/art5.pdf> [Consultado el 12 de marzo de 2019].

Helfant, A., 1967. El arte, un difícil equilibrio. Bienal de Esculturas en el Museo de Arte Contemporáneo. Eva, n. ${ }^{\circ}$ 1172, 22 de septiembre, pp. 30-31.

Helfant, A., 1968. Valentina Cruz, una realidad sin ideal. Eva, n. ${ }^{\circ}$ 1209, 28 de junio, pp. 22-23.

Ikegami, H., 2010. The Great Migrator: Robert Rauschenberg and the Global Rise of American Art. Cambridge, Massachusetts: MIT Press.

Lago, T., 1964. Escándalo en Venecia. Ercilla, n. ${ }^{\circ}$ 1534, pp. 12-13.

Lippard, L., 1970. Pop Art. 3. a ed. Londres: Thames and Hudson.

Madoff, S., 1997. Wham! Blam! How Pop Art Stormed the High-Art Citadel and What the Critics Said. En: S.

Madoff, ed. 1997. Pop Art: A Critical History. California: University of California Press, p.xiii-xx.

Mellado, J. P., 2015. Marta Colvin y el Premio de Escultura en la VII Bienal de São Paulo. En: J. Colvin, ed. 2015. Marta Colvin: escultora. Santiago de Chile: Bodegón Cultural de los Vilos, p.49-57.

Núñez, G., 1993. Retrato hablado: una retrospectiva. Santiago de Chile: Museo de Arte Contemporáneo y Universidad de Chile. 
Ossa, N., 1966. Guillermo Núñez en la Sala de la Universidad de Chile. PEC, 12 de agosto, s. p.

Oyarzún, L., 1969. Arte moderno: presentimiento y preguntas. El Mercurio, 21 de agosto, s. p.

Pérez, A., 1970. La pintura cubana en la Revolución. Atenea, n. 423, pp. 6-23.

Polgovsky Ezcurra, M., 2014. La cita bíblica: iconoclasmo y sacralidad en la estética de la "avanzada”. En: VV. AA. 2014. Ensayos sobre artes visuales. Prácticas y discursos de los años '70 y '80 en Chile. Volumen III. Santiago de Chile: LOM.

Seiberling, D., 1964. Is He the Worst Artist in the U.S.? Life, enero, pp.79-83. En: S. Madoff, ed. 1997. Pop Art: A Critical History. California: University of California Press.

Richard, N., 1986. Margins and Institutions: Art in Chile since 1973. Art \& Text, volumen 21.

Romera, A., 1965. Crónica de Arte. En torno al “pop art”. Atenea, n.o 409, julio-septiembre, pp. 271-277.

Romera, A., 1969. Supuesta peligrosidad del arte. El Mercurio, 29 de febrero, s. p.

Warhol, A., 1963. What is pop art? Art News, noviembre, pp. 24-27. En: S. Madoff, ed. 1997. Pop Art: A Critical History. California: University of California Press. pp. 103-104.

\section{Bibliografía}

Casals Araya, M., 2014. "Chile en la encrucijada". Anticomunismo y propaganda en la "campaña del terror" de las elecciones presidenciales de 1964”. En: T. Harmer, A. Riquelme, eds. 2014. Chile y la Guerra Fría. Santiago de Chile: Ril Editores. pp. 89-132.

Cazanga Moncada, O., 2017. Historia crítica de la educación pública en Chile. Santiago de Chile: RialStat Editores.

García, S. y Berger, D., 2016. La emergencia del pop. Irreverencia y calle en Chile. [en línea] Santiago de Chile: Museo de la Solidaridad Salvador Allende.

Huyssen, A., 1975. The Cultural Politics of Pop: Reception and Critique of US Pop Art in the Federal Republic of Germany. New German Critique, n. ${ }^{0}$ 4, pp. 77-97.

Pollner, E., 1968. Veinte [20] jóvenes pintores chilenos. Santiago de Chile: Editorial Universitaria.

Salazar, G. y Pinto, J., 2002. Historia contemporánea de Chile III. La economía: mercados, empresarios y trabajadores. Santiago de Chile: LOM. 


\section{Soledad García Saavedra es curadora}

(Goldsmiths College, University of London) e historiadora del arte (Universidad de Chile). Es coordinadora de Programas públicos del Museo de la Solidaridad Salvador Allende (MSSA). Sus proyectos de curaduría como Pop crítico y la Emergencia del pop. Irreverencia y calle en Chile (MSSA, 2016) y de investigación (Clark Art Institute, 2018; Fondart, 2019) abordan los cruces críticos del arte pop y la cultura popular en los años sesenta. Fue coordinadora del Centro de Documentación de las Artes Visuales del Centro Cultural La Moneda y editora de los libros Ensayos sobre Artes Visuales (2010-2016). 